\title{
Magnetically Induced
}

National Cancer Institute

\section{Source}

National Cancer Institute. Magnetically Induced. NCI Thesaurus. Code C92074.

Problems due to unintended or excessive movement created by the application of magnetic fields. 